\title{
Prospective Effects of Sexual Victimization on PTSD and Problem
}

\section{Drinking}

\author{
Cynthia J. Najdowskia,b and Sarah E. Ullman, PhD ${ }^{a, c}$ \\ aUniversity of Illinois at Chicago, 1007 West Harrison Street, Chicago, Illinois 60607-7137, United \\ States \\ bcnajdo2@uic.edu \\ cseullman@uic.edu
}

\section{Abstract}

Posttraumatic stress disorder (PTSD) and problem drinking are common and often co-occurring sequelae experienced by women survivors of adult sexual assault, yet it remains unclear whether survivors drink to cope with PTSD symptoms or whether PTSD symptoms are exacerbated by drinking. Thus, we used a cross-lagged panel design with a large $(N=555)$, ethnically diverse sample of women assault survivors to determine whether PTSD prospectively led to problem drinking or vice versa. We also examined whether cumulative sexual victimization experiences related to greater PTSD and problem drinking. Structural equation modeling revealed that child sexual abuse was associated with greater symptoms of PTSD and problem drinking and intervening sexual victimization was associated with greater symptoms of PTSD and problem drinking 1 year later. We found no evidence, however, that PTSD directly influenced problem drinking over the long term, or vice versa. Rather, experiencing revictimization during the study predicted survivors' prospective PTSD and problem drinking symptoms. Implications and recommendations for future research are discussed.

\section{Keywords}

sexual assault; child sexual abuse; revictimization; PTSD; problem drinking

\section{Introduction}

\begin{abstract}
Posttraumatic stress disorder (PTSD) and problem drinking are common and often cooccurring sequelae experienced by women survivors of adult sexual assault (ASA) (Stewart \& Israeli, 2002). Research suggests that comorbid PTSD and problem drinking can be explained by the self-medication model, which proposes that survivors drink to cope with PTSD symptoms (e.g., Cappell \& Greeley, 1987). It has been argued, however, that, although drinking may temporarily relieve trauma-related distress, excessive drinking may exacerbate PTSD symptoms (Volpicelli, Balaraman, Hahn, Wallace, \& Bux, 1999) and may result in chronic PTSD and problem drinking in the long run (Stewart, Pihl, Conrod, \& Dongier, 1998). PTSD
\end{abstract}

Correspondence should be addressed to Cynthia J. Najdowski at the above postal or email addresses, or by telephone (773-720-1579) or fax (312-413-4122).

Publisher's Disclaimer: This is a PDF file of an unedited manuscript that has been accepted for publication. As a service to our customers we are providing this early version of the manuscript. The manuscript will undergo copyediting, typesetting, and review of the resulting proof before it is published in its final citable form. Please note that during the production process errors may be discovered which could affect the content, and all legal disclaimers that apply to the journal pertain. 
resulting from problem drinking could be accounted for by (a) survivors' use of ineffective coping strategies (e.g., drinking to cope) to deal with the trauma, (b) chemical changes in the brain as a consequence of drinking, or (c) increased anxiety and/or arousal caused by drinking. Research, however, has yet to test these hypotheses simultaneously in a sample of women ASA survivors. Thus, we used a cross-lagged panel design to prospectively examine whether (a) PTSD leads to problem drinking, (b) problem drinking leads to PTSD, or (c) each influences the other.

In addition, having a history of child sexual abuse (CSA) is associated with more severe PTSD and more problem drinking in women survivors of ASA (Ullman, Najdowski, \& Filipas, in press). Further, all three of these factors (i.e., prior victimization, PTSD, problem drinking) are associated with risk of revictimization (e.g., Ullman et al., in press; for review, see Ullman \& Najdowski, in press). In fact, the strong association between past victimization and risk for revictimization may be explained by PTSD and problem drinking behaviors that women develop in response to their victimization experiences. In support, Wilson, Calhoun, and Bernat (1999) found that numbing symptoms decreased the ability of sexually revictimized women to recognize risk in a scenario depicting rape. In contrast, arousal symptoms were associated with more risk recognition. Ullman et al. (in press), however, found that victims of adult sexual assault who had a history of child sexual abuse reported having more arousal, reexperiencing, and avoidance symptoms, and those symptoms predicted greater problem drinking which thereby increased their likelihood for experiencing another sexual assault. Problem drinking may increase victims' risk of revictimization through several pathways. For example, alcohol consumption reduces women's intentions and abilities to resist unwanted sexual advances (Testa, VanZile-Tamsen, Livingston, \& Buddie, 2006). Also, women who are incapacitated by alcohol may be targeted by perpetrators who view them as vulnerable (Kilpatrick, Resnick, Ruggiero, Conoscenti, \& McCauley, 2007). Although research has established that prior victimization, PTSD, and problem drinking are robust risk factors for revictimization, it is less clear how cumulative victimization experiences prospectively influence PTSD and problem drinking. Thus, we included CSA and revictimization in our model, and predicted that cumulative victimization experiences would be related to greater PTSD and greater problem drinking in our sample of ASA survivors.

\section{Method}

\subsection{Participants and Procedure}

Advertisements in local newspapers and fliers distributed throughout the Chicago metropolitan area invited women aged 18 or older with unwanted sexual experiences since age 14 to participate in a confidential mail survey. Interested women were mailed the initial survey (i.e., Time 1 [T1]) with a cover letter, information sheet describing the study, informed consent form, a list of community resources for survivors of violence, and a postcard to return if they were interested in participating in a follow-up survey (i.e., Time 2 [T2]). 1,084 women completed the T1 survey (a 90\% response rate) and 909 women expressed interest in completing the follow-up survey. Approximately 1 year later, women were mailed the second survey with an updated community resource sheet. Women received $\$ 20$ for completing each survey. T2 surveys were returned by 625 women-a $69 \%$ response rate. Women who completed only the T1 survey and those who completed both the T1 and T2 surveys did not differ significantly on any variables reported herein (all $t \mathrm{~s}(728-957)=-1.87-1.52, p s \geq .06$; all $\left.\chi^{2} s(1-7,959-969) \leq 7.75, p s \geq .17\right)$. Our final sample included 555 women who reported an ASA at T1 and who completed both waves of data collection. The sample was quite ethnically diverse (40\% Caucasian, 43\% African American, 6\% Hispanic/Latina, 3\% Asian, and 8\% other), and women were 18 to 68 years old $(M=32$ years, $S D=11)$. Fourteen percent of women had graduated from high school and an additional $73 \%$ had attended at least some college. 
Fifty-two percent of women were employed and $56 \%$ of women reported household incomes of less than $\$ 20,000$ per year. Women were treated in accordance with the ethical guidelines of the University of Illinois at Chicago.

\subsection{Measures}

2.2.1 Sexual victimization-Each type of sexual victimization (i.e., CSA, ASA, revictimization) was assessed dichotomously (experienced, not experienced) using the Sexual Experiences Survey (SES; Koss \& Gidycz, 1985). On the T1 survey, the SES assessed completed rape, attempted rape, sexual coercion, or unwanted sexual contact at age 14 years or older (i.e., ASA) and before age 14 years (i.e., CSA). All women in this sample had experienced ASA and 300 women (54\%) had experienced CSA. On the T2 survey, the SES revealed that 248 women $(45 \%)$ had experienced another ASA since the last survey. Although women's victimization experiences were heterogeneous (see Table 1), most involved completed rape.

2.2.2. PTSD symptoms—PTSD symptoms were assessed with the Posttraumatic Stress Diagnostic Scale (PDS; Foa, 1995), a standardized 17-item instrument based on DSM-IV criteria. On a scale ranging from 0 (not at all) to 3 (almost always), women rated how often each symptom (i.e., re-experiencing/intrusion, avoidance/numbing, hyperarousal) had bothered them in relation to the assault during the past 30 days. The PDS has acceptable testretest reliability for a PTSD diagnosis in assault survivors over two weeks $(\kappa=.74$; Foa, Cashman, Jaycox, \& Perry, 1997) and was reliable in our sample $(\alpha=.92)$. Women completed the PDS at T1 $(M=18.84, S D=12.24)$ and T2 $(M=17.86, S D=11.67)$.

2.2.3. Problem drinking symptoms-Problem drinking symptoms were assessed using the Michigan Alcoholism Screening Test (MAST; Selzer, 1971), a standardized 25-item screening instrument for alcohol abuse and dependence, and 4 additional items designed to detect problem drinking specifically in women (e.g., "Has drinking had a harmful effect on your housework or chores around the house?; Richman, 2000). The MAST and supplemental items formed a reliable measure of problem drinking in our sample $(\alpha=.82)$. Past-year problem drinking was assessed at $\mathrm{T} 1(M=6.37, S D=9.55)$, and women responded to the measure at T2 based on their drinking experiences since the last survey $(M=5.95, S D=9.02)$.

\section{Results}

Using a structural equation modeling framework, we conducted an observed variables path analysis to test a cross-lagged, partially mediated model of PTSD and problem drinking in ASA survivors. The model included 555 women who reported a sexual assault at Time 1 and completed both surveys, exceeding the suggested ratio of 10 cases for each model parameter (Kline, 1998). T1 and T2 measures of PTSD symptoms were univariate normal with skew less than 3 and kurtosis less than 3 (Kline, 1998), but our measures of problem drinking had high kurtosis $(\mathrm{T} 1=6.11, \mathrm{~T} 2=4.77)$. Because the measure was not too skewed $(\mathrm{T} 1=2.35, \mathrm{~T} 2=$ 2.23), however, we used the untransformed variable given that effects of violations of normality assumptions regarding kurtosis are minimal in larger samples (Tabachnick \& Fidell, 2001). None of the first-order bivariate correlations was above .80 (see Table 2), indicating that multicollinearity across variables was not a problem with these data at the measurement level (Kline, 1998). Because of significant correlations, PTSD and problem drinking were correlated in the model at both $\mathrm{T} 1$ and $\mathrm{T} 2$.

First, we tested a preliminary model that included all hypothesized paths. Based on the statistical significance of the path coefficients as revealed through maximum likelihood estimation, nonsignificant paths $(p>.05)$ were removed. Specifically, we deleted (a) the direct 
effect of CSA on revictimization, (b) the direct effect of T1 PTSD symptoms on T2 problem drinking, and (c) the direct effect of T1 problem drinking on T2 PTSD symptoms. This allowed us to identify the most parsimonious model, which had sufficiently good fit, $\chi^{2}(6,555)=7.09$, $p=.31(\mathrm{IFI}=1.00, \mathrm{NFI}=.99$, and RMSEA $=.02)($ see Figure 1 for final path model $)$.

As predicted, CSA was associated with greater T1 PTSD symptoms and greater T1 problem drinking symptoms in women ASA survivors. Further, the effect of CSA on sexual revictimization between surveys was completely mediated by T1 symptoms of PTSD and problem drinking. Contrary to the self-medication model, T1 PTSD did not have a direct effect on $\mathrm{T} 2$ problem drinking, and, in contrast to the hypothesis that greater problem drinking leads to more severe PTSD symptoms, T1 problem drinking did not have a direct effect on T2 PTSD. Rather, after controlling for survivors' T1 symptoms, the effects of T1 PTSD and problem drinking symptoms on prospective symptomatology were mediated by intervening sexual revictimization. As predicted, revictimization predicted more T2 PTSD symptoms and greater T2 problem drinking symptoms. Although PTSD and problem drinking were significantly correlated at $\mathrm{T} 1$, they were not associated at $\mathrm{T} 2$.

\section{Discussion}

Although T1 PTSD and T2 problem drinking were significantly correlated at the bivariate level, we found no evidence that PTSD directly influenced problem drinking over the long term. This is contrary to the self-medication model but consistent with other research showing null effects of PTSD on prospective heavy or problem drinking (e.g., Testa, Livingston, \& Hoffman, 2007). In addition, T1 problem drinking and T2 PTSD were significantly correlated at the bivariate level but problem drinking did not have a direct effect on PTSD symptoms over time. Rather, our results suggest that PTSD only influences prospective problem drinking, and vice versa, in women who experience further sexual revictimization. That is, the sequelae women experience as a consequence of CSA and ASA increase their risk for experiencing subsequent sexual victimization, which exacerbates those same symptoms and also increases women's risk of developing other symptoms. Although not predicted a priori, this finding is consistent with other analyses of these data showing effects of drinking to cope with distress, negative reactions, and traumatic life events on problem drinking in revictimized women but not in other women (Ullman \& Najdowski, 2009).

The prospective effects of PTSD and problem drinking on each other via revictimization were stronger for women who had experienced more prior victimizations (i.e., both CSA and ASA) than for other women (i.e., victims of ASA only). The effect of CSA on prospective PTSD or problem drinking was also mediated by revictimization, but, of interest, the effect of CSA on revictimization was also indirect, mediated by T1 measures of PTSD and problem drinking. Our results corroborate a wealth of other research showing that PTSD and problem drinking are risk factors for revictimization (see Ullman \& Najdowski, in press), and suggest that these are particularly important outcomes for understanding victims' risk for revictimization. Future research should continue to study the pathways by which victimization sets the stage for experiencing additional sexual assaults, as well as the long-term consequences of being repeatedly victimized.

These findings are also consistent with other research suggesting that proximal assaults (i.e., ASA) rather than distal assaults (i.e., CSA) are more important for understanding women's vulnerability for future sexual victimization (e.g., Gidycz, Coble, Latham, \& Layman, 1993; Himelein, 1995) and psychological outcomes (Nishith, Mechanic, \& Resick, 1990). It may be that proximal assaults mask the effects of distal assaults. Because all of the women in our sample had experienced ASA, however, we were not able to directly compare the relative 
contributions of CSA and ASA to subsequent revictimization or prospective PTSD or problem drinking.

This study was limited by having only two waves of data collected from survivors who varied at baseline in time since they had been sexually assaulted. This large sample was diverse in terms of ethnicity and socioeconomic status, however, and included survivors who can be difficult to reach with traditional random sampling methods (e.g., women without telephones, in shelters). In addition, many survivors experienced a new ASA over the 1-year study period. Despite variation among women in this nonrepresentative community sample, our model predicting prospective symptomatology fit the data well and suggests that current theories explaining comorbid PTSD and problem drinking in ASA survivors need to be modified to account for repeated sexual victimization.

Using the MAST to measure problem drinking in our nonclinical sample is another study limitation, although Shields, Howell, Potter, and Weiss (2007) recently concluded that the MAST is generally an acceptable measure in most research situations. Problems associated with this measure may result from its reliance on responses to face valid items: Participants may not answer honestly regarding the extent of their problem drinking. Also, women's selfreports on this measure may have reflected distress rather than actual problem drinking, which, as suggested by Stewart et al. (1998), may explain the link between PTSD and substance use.

This study suggests that the cycle of effects between sexual victimization, PTSD, and problem drinking has the potential to be quite devastating for victims. Future longitudinal research should examine how specific coping strategies (e.g., drinking to cope, Kaysen et al., 2006; Ullman \& Najdowski, 2009) and other modifiable psychosocial factors relate to PTSD and problem drinking to reduce these outcomes in women survivors. Research should also seek to understand exactly how these outcomes influence women's likelihood of experiencing further assault (e.g., impaired risk judgments; Wilson, Calhoun, \& Bernat, 1999), and how interventions can be developed to decrease women's vulnerability for experiencing any sexual assault.

\section{Acknowledgments}

This research was supported by National Institute on Alcohol Abuse and Alcoholism grant R01 \#13445 to Sarah E. Ullman. We acknowledge Henrietta Filipas, Stephanie Townsend, Laura Starzynski, and Kelly Kinnison for assistance with data collection.

\section{References}

Cappell, H.; Greeley, J. Alcohol and tension reduction: An update on research and theory. In: Blane, HT.; Leonard, KE., editors. Psychological theories of drinking and alcoholism. New York: Guilford; 1987. p. 15-54.

Foa, EB. Posttraumatic Stress Diagnostic Scale Manual. Minneapolis, MN: National Computer Systems, Inc.; 1995.

Foa EB, Cashman L, Jaycox L, Perry K. The validation of a self-report measure of PTSD: The Posttraumatic Stress Diagnostic Scale. Psychological Assessment 1997;9:445-451.

Gidycz CA, Coble CN, Latham L, Layman MJ. Sexual assault experience in adulthood and prior victimization experiences. Psychology of Women Quarterly 1993;17:151-168.

Himelein MJ. Risk factors for sexual victimization in dating. Psychology of Women Quarterly 1995;19:31-48.

Kaysen D, Dillworth TM, Simpson T, Waldrop A, Larimer ME, Resick PA. Domestic violence and alcohol use: Trauma-related symptoms and motives for drinking. Addictive Behaviors 2006;32:12721283. [PubMed: 17098370] 
Kilpatrick, DG.; Resnick, HS.; Ruggiero, KJ.; Conoscenti, LM.; McCauley, J. Drug facilitated, incapacitated, and forcible rape: A national study. U.S. Department of Justice; 2007. Final Report NCJRS Document \# 219181.

Koss MP, Gidycz CA. The sexual experiences survey: Reliability and validity. Journal of Consulting and Clinical Psychology 1985;53:442-443.

Nishith P, Mechanic MB, Resick PA. Prior interpersonal trauma: The contribution to current PTSD symptoms in female rape victims. Journal of Abnormal Psychology 2000;109:20-25. [PubMed: 10740932]

Richman JA. Personal communication. 2000 December;

Selzer ML. The Michigan Alcoholism Screening Test: The quest for a new diagnostic instrument. American Journal of Psychiatry 1971;127:1653-1658. [PubMed: 5565851]

Shields AL, Howell RT, Potter JS, Weiss RD. The Michigan Alcoholism Screening Test and its shortened form: A meta-analytic inquiry into score reliability. Substance Use \& Misuse 2007;42:1783-1800. [PubMed: 17934995]

Stewart, S.; Israeli, A. The violence and addiction equation: Theoretical and clinical issues in substance abuse and relationship violence. In: Wekerle, C.; Hall, AM., editors. Substance abuse and cooccurring psychiatric disorders in victims of intimate violence. New York: Brunner-Routledge; 2002. p. $98-122$.

Stewart SH, Pihl RO, Conrod PJ, Dongier M. Functional associations among trauma, PTSD, and substance-related disorders. Addictive Behaviors 1998;28:797-812. [PubMed: 9801717]

Testa M, Livingston J, Hoffman J. Does sexual victimization predict subsequent alcohol consumption? A prospective study among a community sample of women. Addictive Behaviors 2007;32:29262939. [PubMed: 17597304]

Ullman SE, Najdowski CJ. Revictimization as a moderator of psychosocial risk factors for problem drinking in female sexual assault survivors. Journal of Studies on Alcohol and Drugs 2009;70:4149. [PubMed: 19118390]

Ullman, SE.; Najdowski, CJ. Vulnerability and protective factors for sexual violence. In: White, J.; Koss, M., editors. Violence against women and children. Washington, DC: American Psychological Association; in press

Ullman SE, Najdowski CJ, Filipas HH. Child sexual abuse, PTSD, and substance use: Predictors of revictimization in adult sexual assault survivors. Journal of Child Sexual Abuse. in press

Volpicelli J, Balaraman G, Hahn J, Wallace H, Bux D. The role of uncontrollable trauma in the development of PTSD and alcohol addiction. Alcohol Research and Health 1999;23:256-262. [PubMed: 10890822]

Wilson AE, Calhoun KS, Bernat JA. Risk recognition and trauma-related symptoms among sexually revictimized women. Journal of Consulting and Clinical Psychology 1999;67:705-710. [PubMed: 10535237] 


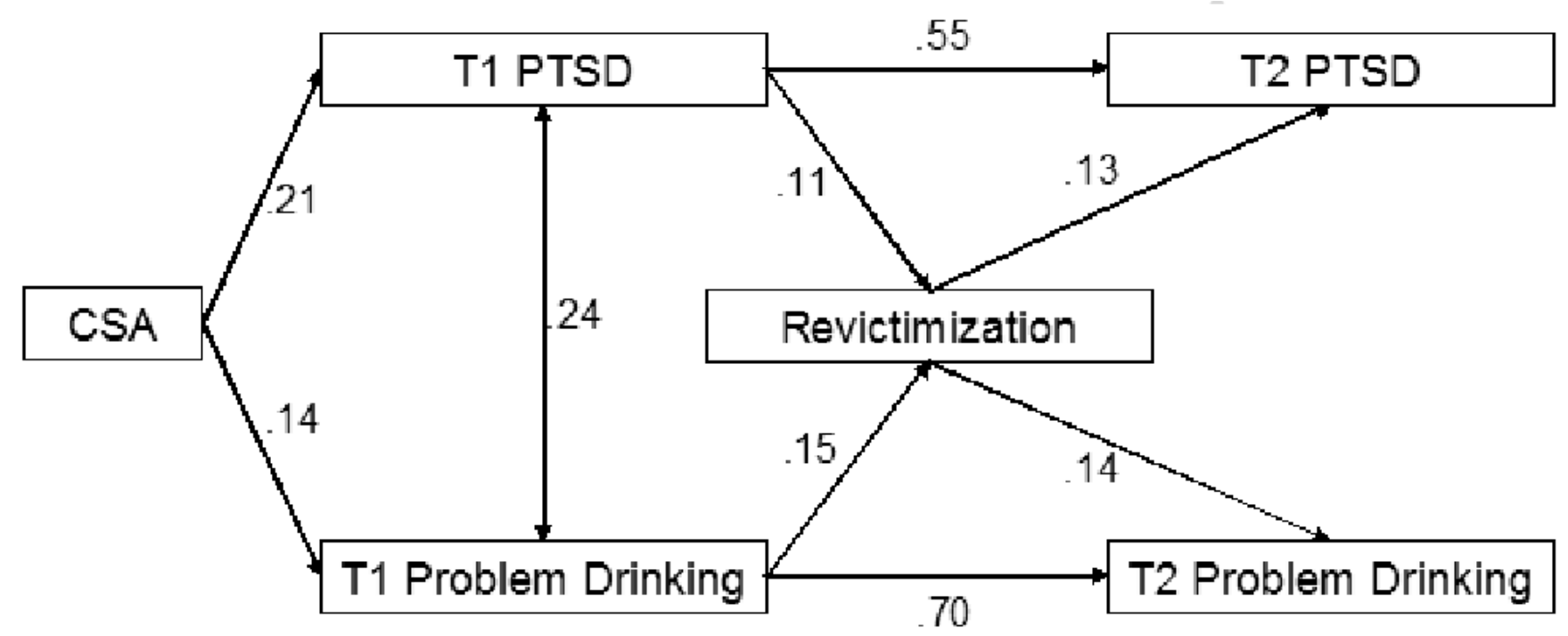

Figure 1.

Final Model of the Relations among CSA, Sexual Revictimization, PTSD Symptoms, and Problem Drinking.

Note: $\chi^{2}(6,555)=7.09, p=.31 ; \mathrm{IFI}=1.00 ; \mathrm{NFI}=.99 ;$ and $\mathrm{RMSEA}=.02$. 
Table 1

Types of Sexual Victimization Experienced by Participants.

\begin{tabular}{lccc}
\hline & $\begin{array}{c}\text { Adult Sexual Assault } \\
(\boldsymbol{N}=\mathbf{5 5 5})\end{array}$ & $\begin{array}{c}\text { Child Sexual Abuse } \\
(\boldsymbol{n}=\mathbf{3 0 0})\end{array}$ & $\begin{array}{c}\text { Revictimization } \\
(\boldsymbol{n}=\mathbf{2 4 8})\end{array}$ \\
\hline Completed rape & $76 \%$ & $47 \%$ & $44 \%$ \\
Attempted rape & $10 \%$ & $17 \%$ & $17 \%$ \\
Sexual coercion & $10 \%$ & $6 \%$ & $25 \%$ \\
Unwanted sexual contact & $4 \%$ & $31 \%$ & $14 \%$ \\
\hline
\end{tabular}




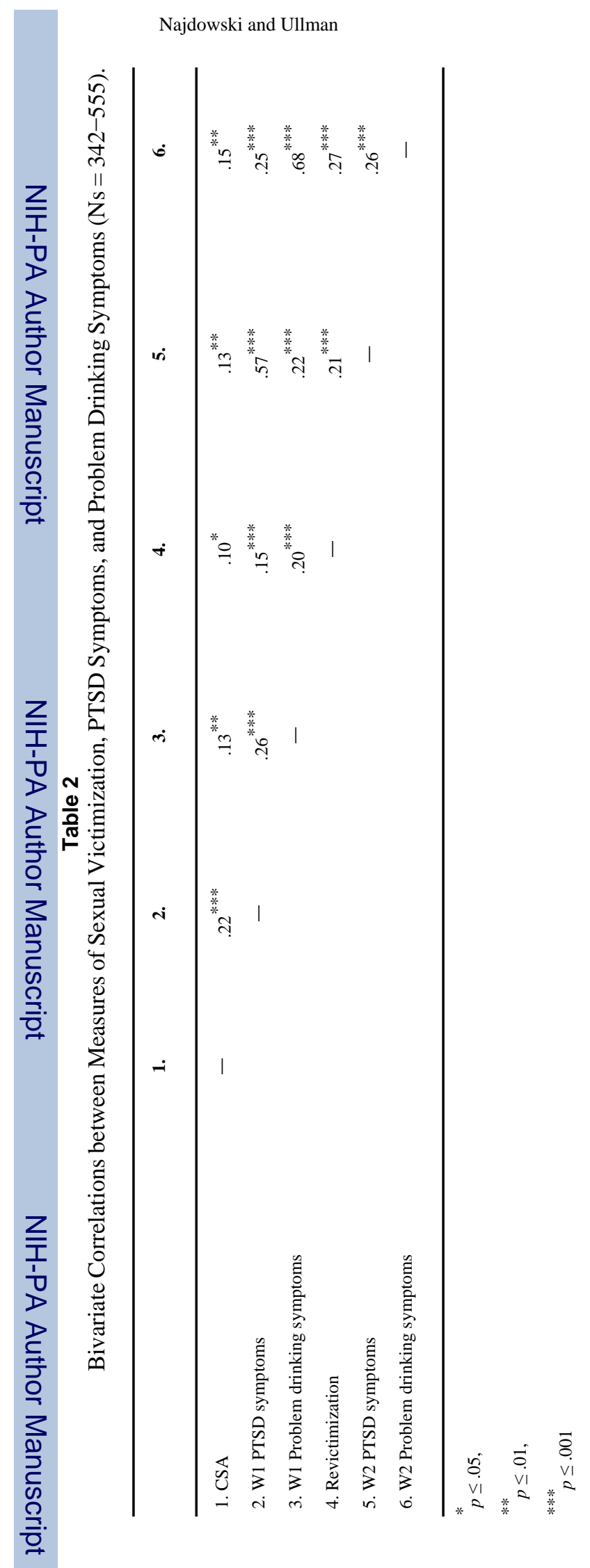

Page 9 